\title{
CARACTERIZACIÓN LIMNOLÓGICA DE LA COROMINA, UNA LAGUNA HIPEREUTRÓFICA DEL SISTEMA LACUSTRE DE BANYOLES
}

\author{
C. M. Borrego y L. J. García-Gil \\ Instituto de Ecología Acuática y Departamento de Biología, Facultad de Ciencias Experimentales y de la Salud. \\ Universidad de Girona, Hospital,6. 17071. GIRONA.
}

Palabras clave: hipereutrofia, holornixis, anoxia, bacterias fototróficas del azufre, ecología microbiana, Chlorobium, Chromatium, Pelodictyon.

\begin{abstract}
LIMNOLOGICAL CHARACTERIZATION OF "LA COROMINA", A HYPERTROPHIC LAGOON OF THE BANYOLES LACUSTRINE AREA

The limnological dynarnics of La Corornina, an holomictic and hypereutrophic lagoon of the Banyoles lacustrine system, has been studied during the 1992 annual cycle. The lagoon has a karstic origin and its depth (between 5 and $7 \mathrm{~m}$ ) depends on the balance of rainfall, evaporation and the water consumption for irrigation. The hypereutrophic state of the lagoon is due to the high inputs of organic matter corning from the adjacent crops and a cattle farm. During sumrner La Corornina registered a stratification period that finished at the end of october with the total rnixing of the water column. During the mixing period the whole water colurnn was cornpletely anaerobic with sulfide concentrations up to $0.6 \mathrm{mmol} 11$. At the stratification period, hypolimnetic sulfide concentrations reached $0.8 \mathrm{mmol} \mathrm{1^{-1 }}$ whereas the epilimnetic oxygen distribution fluctuated between supersaturation periods $(>200 \%)$ and almost completely anaerobic seasons $\left(<0.2 \mathrm{mg} \mathrm{l}^{-1}\right.$ of dissolved oxygen). Maximal concentrations of $1.9 \mathrm{mg} \mathrm{l}^{-1}$ and $834 \mu \mathrm{g} 1^{\prime}$ of total phosphorus and chlorophyll $a$, respectively, have rneasured in the water colurnn, demonstrating the hypereutrophic status of the lagoon. Microbial photosynthetic populations were represented by both algal cornmunities and phototrophic sulphur bacteria. The algal communities were dorninated by Chlamydomonas sp. and Chlorella sp. and the bacteria1 ones by Pelodictyon clathratiforme, which reached maxirnum values of $400 \mathrm{rng}$ m-3 of bacteriochlorophyll $d$. Other species of this group as Chlorobium limicola and the consortium "Chlorochromatium aggregatum" and several Chromatiaceae species (Thiocapsa roseopersicina, Thiodictyon elegans and Chromatium okenii) were also observed. The comparison of the results with previous data revealed that the actual status of La Coromina and the extreme fluctuations observed on its lirnnological dynarnics are found to be closely related with the increase of organic wastes registered during the last years.
\end{abstract}

\section{INTRODUCCIÓN}

La progresiva degradación que sufren los ecosistemas acuáticos es uno de los problemas más graves con los que se enfrenta actualmente nuestro entorno natural. El vertido de residuos orgánicos, la fertilización de las aguas con abonos agrícolas y la creciente industrialización y urbanización de zonas rurales ha incidido negativamente en la calidad de los sistemas acuáticos. Debido a estos hechos el numero de lagos y lagunas con problemas de eutrofización ha aumentado considerablemente en los últimos años.
La eutrofización de aguas continentales ha sido estudiada por diversos autores (VOLLENWEIDER, 1968, 1982; IMBODEN, 1974; GLIWICZ \& KOWALCZEWSKI, 1981; HENDERSON-SELLERS \& MARKLAND, 1987) y son frecuentes los estudios sobre ecosistemas acuáticos eutróficos e hipereutróficos y su posible recuperación en la bibliografía especializada (MIDDLEBROOKS et al., 1975; JøRGENSEN, 1976; KAMP-NIELSEN, 1980; SAS, 1989). A pesar de que el sistema lacustre de Banyoles esta constituido por un gran numero de lagos y lagunas, los trabajos de investigación acerca de su estado trófico se 
han centrado básicamente en el lago de Banyoles (ABELLA et al., 1986, GARCÍA-GIL et al., 1990) y en la laguna del Vilar (BRUNET et $a l ., 1990$ ), siendo escasos los que hacen referencia a otras lagunas de la zona (RIERA, 1988).

La Coromina puede considerarse como la única laguna hipereutrófica existente en el complejo lacustre de Banyoles. A la escasa renovación del agua se une el hecho de que recibe el vertido de residuos orgánicos derivados de una granja porcina cercana y la entrada de fertilizantes agrícolas a través de la lixiviación de los campos de cultivo adyacentes. Dicho vertido provoca una alta contaminación orgánica en la laguna que ha conducido a un estado de hipereutrofia de difícil recuperación. En este trabajo se presenta la dinámica limnológica de La Coromina durante un ciclo anual, haciendo especial hincapié en la evolución de los principales parámetros indicadores de su estado trófico y en la distribución de las diferentes poblaciones de microorganismos fotosintéticos que se desarrollan en la laguna.

\section{ÁREA DE ESTUDIO}

La laguna de Coromina forma parte de un conjunto de lagunas de origen cárstico localizadas en el valle de Sant Miquel de Campmajor (Banyoles, Girona). La laguna Coromina es la mayor de la zona (64 $\mathrm{m}$ de diámetro) y se encuentra en un hundimiento completamente circular de elevada pendiente $\left(>50^{\circ}\right.$ ) (Figura 1). La laguna no recibe un aporte de agua subterránea como ocurre en la mayoría de lagunas de la zona. Por este motivo el nivel de agua depende exclusivamente del balance entre el régimen de precipitaciones, la evaporación y la utilización de sus aguas para el regadío. Son frecuentes por tanto las variaciones estacionales en su profundidad. La máxima registrada durante el presente ciclo fué de $7 \mathrm{~m}$ y la mínima de $4,5 \mathrm{~m}$. La profundidad máxima media de La Coromina se situó en $5 \mathrm{~m}$.

\section{MATERIAL Y MÉTODOS}

El muestreo se realizó en el punto de máxima profundidad de la laguna. Las muestras de agua se tomaron mediante un sistema de bombeo con doble cono (JØRGENSEN et al., 1979), almacenándose en botellas de plástico de 11 de capacidad cerradas herméticamente. La temperatura y la conductividad se determinaban "in situ" mediante un conductivímetro WTW modelo LF-191. La penetración

\section{Laguna COROMINA}

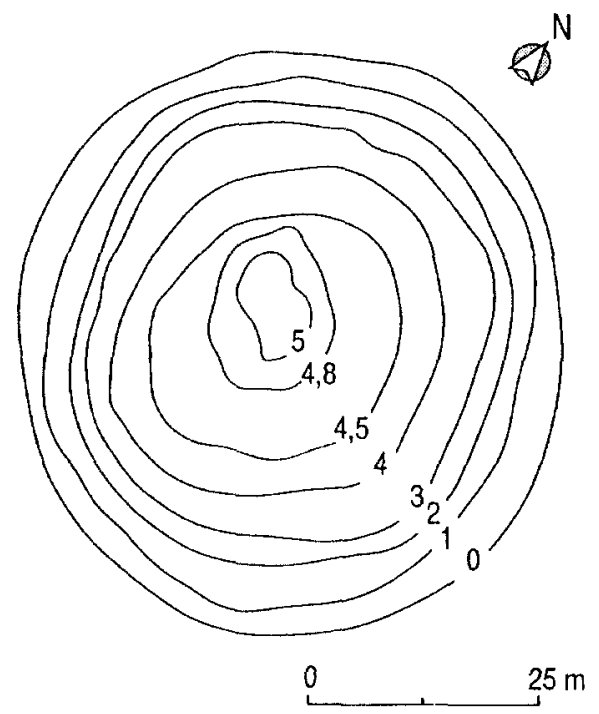

FIGURA 1.- Batimetría de la Laguna Coromina donde se observa su morfología completamente circular. Modificado de Riera (1988). FIGURE 1.- Bathymetric map of the Coromina lagoon. Redrawn after Riera (1988)

de la luz se registró con un cuantómetro de tipo esférico Biospherical Instruments QSP-170 con esfera de teflón de $1,9 \mathrm{~cm}$ de diámetro. El PAR (Photosynthetic Active Radiation) obtenido se expresó en $\mu \mathrm{E} \mathrm{m}^{-2} \mathrm{~s}^{-}$.

Para el análisis químico las muestras de agua se procesaban en el laboratorio pocas horas después de su recolección. El pH se determinaba mediante un pH-metro CRISON modelo 506. El potencial de Óxido-Reducción (Eh) se midió con un electrodo combinado de platino Metrom modelo 6.0401.100. La concentración de oxígeno se registraba in situ mediante un oxímetro Yellow Spring Instruments modelo 57. La concentración de sulfhídrico se determinó siguiendo el método del azul de leucometileno (PACHMAYR, 1960). Para dicho análisis, las muestras eran fijadas previamente en el campo añadiendo $\mathrm{NaOH}$ $1 \mathrm{M}$ y acetato de zinc $1 \mathrm{M}$ al $10 \%$ final. Los análisis de fósforo total (P-PT) y de amonio $\left(\mathrm{NH}_{4}^{+}\right)$se realizaban siguiendo los métodos descritos por GOLTERMAN et al. (1978). Los sulfatos se analizaban siguiendo el método turbidimétrico del cloruro de bario (ASTM STANDARDS, 1981).

La determinación de las diferentes comunidades de microorganismofotosintéticos (tanto algas como bacterias fototróficas del azufre) se realizó mediante el análisis de sus pigmentos fotosintéticos, obteniendo de esta forma 
una estima de su biomasa. Con este fin se filtraban $500 \mathrm{ml}$ de muestra a través de un filtro de nitrato de celulosa de $47 \mathrm{~mm}$ de diámetro y $0,45 \mathrm{pm}$ de tamaño de poro. El filtro se cubría previamente con una fina capa de carbonato magnésico al 2,5\%. La capa de $\mathrm{MgCO}_{3}$ que contenía las células se resuspendía en $5 \mathrm{ml}$ de acetona en un tubo roscado de vidrio preservado de la luz. Los tubos se almacenaban 24 horas a $-20^{\circ} \mathrm{C}$ para asegurar la completa extracción de los pigmentos. Pasado este periodo, los extractos se centrifugaban a $4500 \mathrm{rpm}$ durante $20^{\prime}$ y se procedía a su análisis espectrofotométrico, utilizando un Spectronic Milton-Roy 3000. Las concentraciones de Clorofila a (Clor a) y Bacterioclorofila d (BClor d) se calcularon utilizando las fórmulas de SMITH \& BENITEZ (1955), TAKAHASHI \& ICHIMURA (1968) y GLOE et al. (1975). Las concentraciones obtenidas se expresaron en $\mathrm{pg} \mathrm{l}^{-1}$.

La identificación de las diferentes especies de bacterias fototróficas del azufre se realizó en base a sus pigmentos fotosintéticos y en la observación de las muestras naturales al microscopio óptico, en este caso el modelo utilizado fue un Zeiss Axioscop HDIC.

\section{RESULTADOS Y DISCUSIÓN}

\section{Características físico-químicas.}

La laguna presentó una estratificación térmica que se inició en el mes de mayo y continuó hasta finales de octubre (Figura 2). Durante este periodo se registró un episodio de desestabilización, localizado en el mes de julio, de-

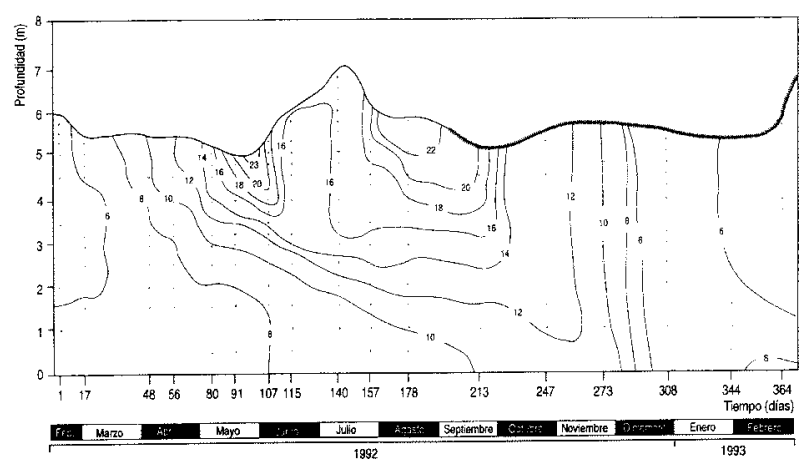

FIGURA 2.- Distribución espacio-temporal de la temperatura (en ${ }^{\circ} \mathrm{C}$ ) en la Coromina durante el período de estudio (febrero 1992-febrero 1993). Debido a las oscilaciones en el nivel del agua, la profundidad se ha referido al fondo de la laguna como único punto fijo. Los puntos grises representan los puntos de muestreo.

FIGURE 2.- Time-Depth distribution of temperature $\left({ }^{\circ} \mathrm{C}\right)$ in La Coromina during the study period. Grey dots represent the sampling depths. bido a un intenso régimen de precipitaciones. El epilimnion osciló entre los 3-4 m de profundidad y el hipolimnion entre los 2-3 m. En el mes de octubre se produjo la mezcla total de la columna de agua. Durante los meses de diciembre y enero la superficie de la laguna se heló por completo, formándose una capa de hielo de $2,5 \mathrm{~cm}$ de espesor.

La distribución espacio-temporal de la conductividad se muestra en la figura 3. Aunque la laguna puede catalogarse como holomíctica, durante el periodo estudiado la mezcla de la columna de agua no fué total. En la columna de agua se generó un gradiente de conductividad ascendente a medida que se avanzaba en profundidad. Este gradiente, aunque suave, mantuvo una capa de agua más densa en el fondo de la laguna de aproximadamente $1 \mathrm{~m}$ de espesor, que no se mezcló con las capas superiores durante el período invernal (Figura 3, área sombreada). Esta estratificación química fué generada por la presencia de gran cantidad de substancias orgánicas derivadas de intensa actividad microbiana del sedimento. En este sentido, puede decirse que la Coromina desarrolló una meromixis biogénica, difiriendo notablemente de otros lagos y lagunas del sistema lacustre de Banyoles (por ejemplo las cubetas III y IV del lago de Banyoles o la laguna del Vilar), que presentan meromixis crenogénica.

Los valores de $\mathrm{pH}$ se mantuvieron prácticamente estables (entre 6,9 y 7,2 ) en la mayor parte de la columna de agua excepto durante los meses de marzo-abril donde aumentaron considerablemente en los dos primeros metros (valores de 8-9) (Figura 4). Este aumento estuvo relacio-

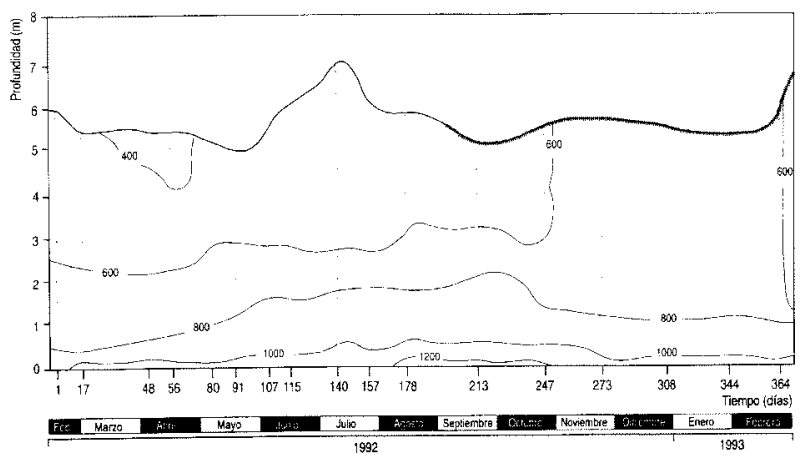

FIGURA 3.- Distribución espacio-temporal de los valores de conductividad (en $\mu \mathrm{S}$ cm-') en La Coromina. El gradiente de conductividad, aunque suave, mantuvo aislada una masa de agua en profundidad durante todo el período estudiado (área sombreada).

FIGURE 3.- Time-Depth distribution of conductivity values (in $\mu S$ $\mathrm{cm}^{-1}$ ) in La Coromina. The conductivity gradient isolated a dense water layer at the bottom of the laggon dunng the whole study penod (shaded area). 


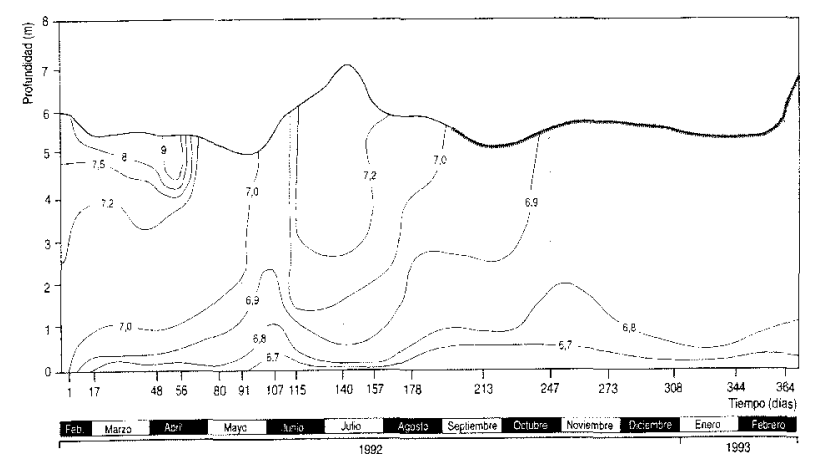

FIGURA 4.- Distribución espacio-temporal de los valores de pH. Anivel de sedimento el $\mathrm{pH}$ registró valores inferiores a los detectados en la columna de agua debido a la acumulación de substancias orgánicas en esta zona.

FIGURE 4.- Time-Depth distribution of $\mathrm{pH}$ values in La Coromina. At the sediment level $\mathrm{pH}$ values decreasaed as a result of the accumulation of organic acids produced by bacterial metabolism.

nado con la intensa actividad fotosintética registrada en esta zona durante este período. La producción primaria tiene un claro efecto sobre el pH del medio debido al desequilibrio del sistema tampón carbonato provocado por la fijación fotosintética de CO, (MARGALEF, 1983). Por otra parte, a nivel de sedimento la acumulación de substancias orgánicas, principalmente ácidos orgánicos derivados de actividad bacteriana fermentadora en el fondo de la laguna, contribuyó al descenso de los valores de $\mathrm{pH}$ en estas zonas $(6,7)$.

La distribución del oxígeno disuelto presenta las características típicas de otros ecosistemas hipereutróficos, con fluctuaciones extremas que van desde periodos de sobresaturación a otros con anoxia total de la columna de agua (BARICA, 1979). En la figura 5 se muestra la distribución espacio-temporal del oxígeno disuelto durante el ciclo estudiado. Durante los meses de febrero a abril, la laguna registró un periodo de sobresaturación ( $>200 \%$ ), con concentraciones superiores a los $20 \mathrm{mg} \mathrm{1}^{-1}$. Este fenómeno responde a la presencia de un "bloom" algal que se desarrolló en esta zona, alcanzando los $800 \mathrm{mg} \mathrm{m}^{-3}$ de Clor $\underline{a}$. Por debajo de $\operatorname{los} 2$ metros el oxígeno se agotaba rápidamente dando paso a un hipolimnion completamente anóxico, que se mantuvo en este estado durante todo el periodo de estratificación (Figura 5). El epilimnion se mantuvo ligeramente oxigenado durante la estratificación estival (alrededor de $2 \mathrm{mg}^{-1}$ ) gracias al episodio de intensas precipitaciones (julio) que contribuyó a una ligera re-oxigenación del mismo. Por el contrario, la mezcla de la columna de

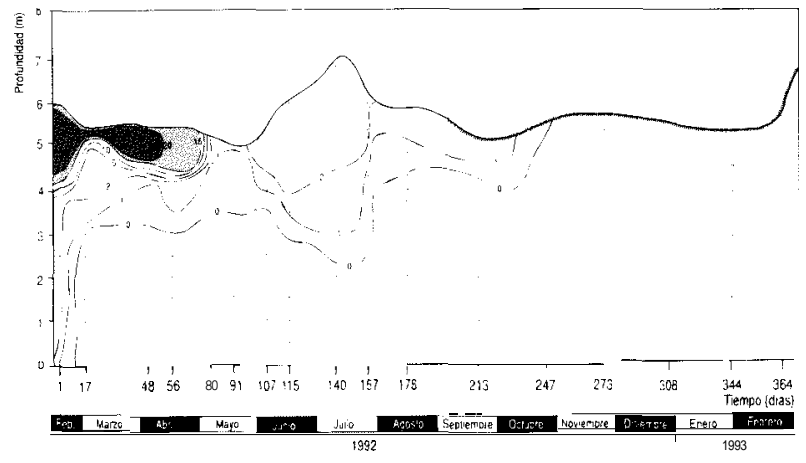

FIGURA 5.- Distribución espacio-temporal de la concentración de oxígeno disuelto (en $\mathrm{mg} \mathrm{l}^{-1}$ ) en La Coromina. Durante la primavera el epilimnion registró sobresaturación de oxígeno (>200\%) como consecuencia de la elevada actividad fotosintética de la comunidad fitoplanctónica (área sombreada).

FIGURE 5.- Time-Depth distribution of dissolved oxygen concentration (in $\mathrm{mg}^{-1}$ ) in La Coromina. During spring an oxygen supersaturation period of up to $200 \%$ was detected in the epilimnion (shaded area) due to the high photosynthetic activity of the phytoplankton community.

agua durante el mes de octubre no contribuyó a la oxigenación de la misma debido a la elevada demanda de oxígeno requerida para la oxidación de la materia orgánica sedimentada (valores medios de P-PT y $\mathrm{NH}_{4}{ }^{+}$en el sedimento de $5,2 \mathrm{mg} \mathrm{l}^{-1}$ y $49,1 \mathrm{mg} \mathrm{l'}$, respectivamente). A finales de octubre se estableció la anoxia en la totalidad de la columna de agua.

La anoxia del hipolimnion y la presencia de sulfatos en

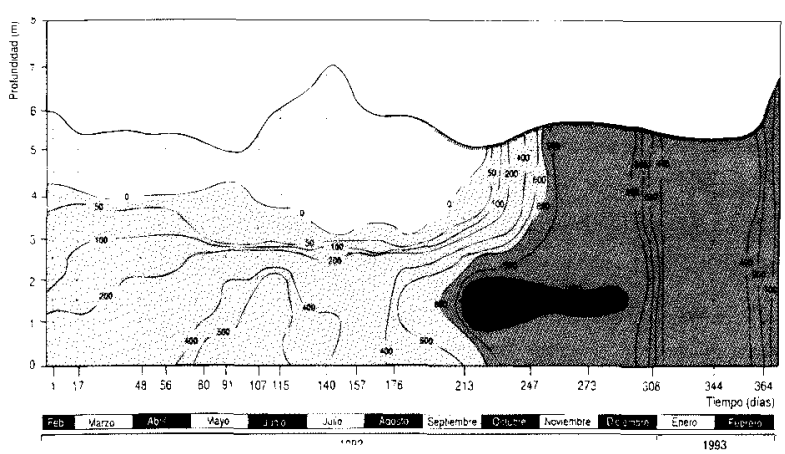

FIGURA 6.- Distribución espacio-temporal de la concentración de sulfhídrico (en $\mu \mathrm{mol} \mathbf{l}^{\mathrm{I}}$ ).

FIGURE 6.- Time-Depth distribution of the sulfide concentration (in $\mu \mathrm{mol}^{1}{ }^{1}$ ) in the lagoon during the study period.

el agua (= $2 \mathrm{mmol} \mathrm{l}^{-1}$ de concentración media) favoreció la producción de sulfhídrico como resultado de la actividad sulfato reductora básicamente en el sedimento. En la figu- 
ra 6 se muestra la distribución espacio-temporal de este compuesto en la laguna durante el periodo estudiado. Como puede observarse el sulfhídrico ocupó la totalidad del volumen del hipolimnion anóxico alcanzando concentraciones máximas de 0,9-1 mmol 1-'.

\section{Comunidades microbianas fotosintéticas}

La acumulación de oxígeno en el epilimnion detectada durante la primavera estuvo ligada a una intensa actividad fotosintética por parte de una comunidad fitoplanctónica, constituida principalmente por Clorofíceas (en concreto de los géneros Chlamydomonas y Chlorella), Diatomeas (principalmente Cyclotella) y Euglenofíceas (Euglena). Este "bloom" se localizó en los dos primeros metros, durante los meses de febrero, marzo y abril, alcanzando valores máximos de 600-800 $\mu \mathrm{g}$ 1-' de Clor a (Figura 7). La integración de la clorofila a epilimnética durante este periodo se calculó del orden de $426 \mathrm{mg} \mathrm{m}^{-2}$. Según STEEMANN-NIELSEN (1962) el valor máximo de Clor a útil es de $400 \mathrm{mg} \mathrm{m}^{-2}$, inferior al obtenido en el caso de La Coromina. Esta observación pone de manifiesto la inestabilidad de la propia comunidad debido a la elevada biomasa alcanzada. Esta inestabilidad derivó en la muerte catastrófica de la comunidad a finales del mes de abril. Fenómenos catastróficos de este tipo son característicos de ecosistemas hipereutróficos como el que nos ocupa (HENDERSON-SELLERS \& MARKLAND, 1987).

Tras la desaparición de la comunidad fitoplanctónica, la superficie de la laguna fué colonizada por una población

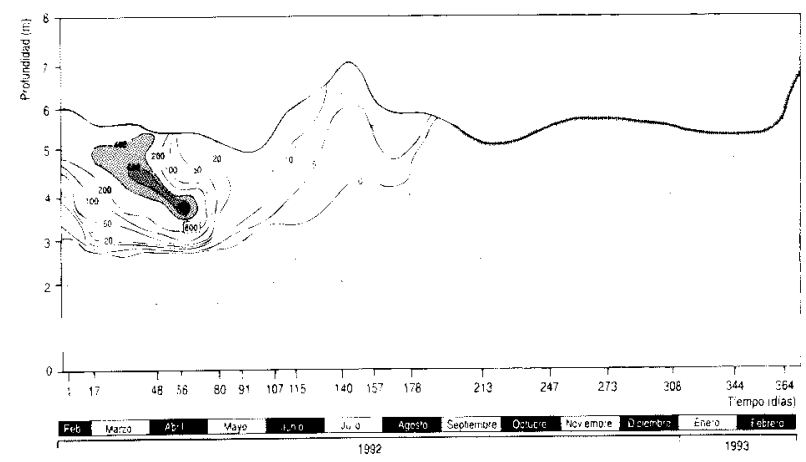

FIGURA 7.- Distribución espacio-temporal de la concentración de Clor

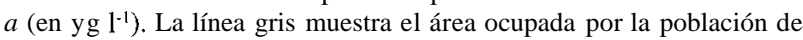
Lemna minor.

FIGURE 7.- Time-Depth distribution of Chl $a$ concentration (in $\mathrm{yg} \mathrm{l}^{-1}$ ) in the lagoon during the study period. A population of Lemna mmor was established at the surface of the lagoon from mid august to the end of the study period (grey line) de Lemna minor, que constituyó un tapiz uniforme en toda el área ocupada. Esta población se mantuvo estable durante todo el periodo estudiado y no pareció verse afectada por las concentraciones de sulfhídrico que se detectaron en las capas superficiales de la laguna (máximo de 0,9-1 mmol $\mathrm{l}^{-1}$ de $\mathrm{H}_{2} \mathrm{~S}$ a $0 \mathrm{~m}$ ). La población de Lemna impidió el desarrollo de otras comunidades fitoplanctónicas debido al filtro biológico respecto a la intensidad de la luz que suponía dicha lámina superficial. La atenuación de la luz atribuible a la capa de Lemna minor fué estimada del orden del 18,3\% en los 5 primeros cm de la columna de agua. Este efecto de sombreado combinado con la presencia de sulfhídrico en el epilimnion (concentraciones de hasta $0,4 \mathrm{mmol} \mathrm{l}^{-1}$ ) fué suficiente como para limitar el crecimiento fitoplanctónico durante las últimas fases de la estratificación estival (meses de agosto-octubre).

La presencia de sulfhídrico en la columna de agua favoreció el desarrollo de bacterias fototróficas del azufre que pasaron a representar el papel que anteriormente habian desempeñado las algas como productores primarios. Las bacterias verdes fototróficas del azufre, y en concreto la especie Pelodictyon clathratiforme, dominaron la columna de agua durante la mayor parte de periodo estudiado. En la figura 8 se muestra la distribución espacio-temporal de la BClor d, el principal pigmento fotosintético de Pelodictyon. La población se mantuvo estable durante todo el ciclo, llegando a alcanzar valores de 400-600 $\mathrm{pg}^{-1} \mathrm{de}$ BClor d una vez desapareció la comunidad fitoplanctónica. Este hecho estuvo relacionado con el aumento de luz disponible para la fotosíntesis bacteriana una vez desapareció el filtro biológico algal. Pelodictvon dominó la tota-

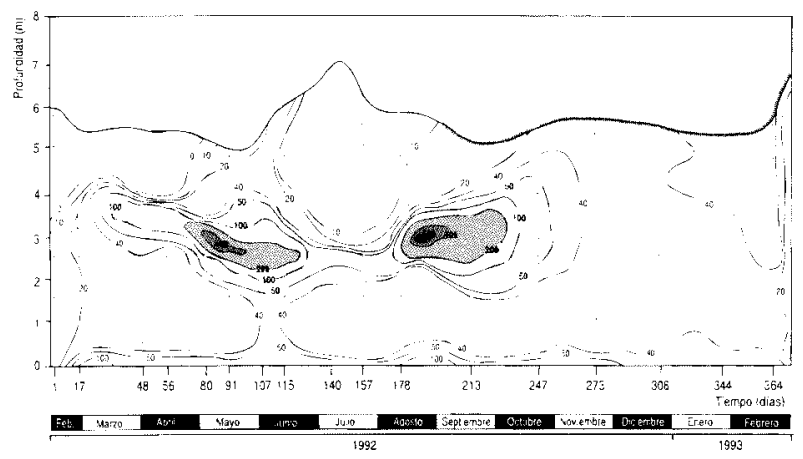

FIGURA 8.- Distribución espacio-temporal de la concentración de BClor d (en $\mu \mathrm{g}^{+1}$ ) correspondiente a la población de Pelodictyon clathratiforme. La línea gris muestra el área acupada por la población de Lemma nzior.

FIGURE 8.- Time-Depth distribution of $\mathrm{BChl} d$ concentration (in $\mu \mathrm{g}$ $\left.1^{1}\right)$ corresponding to the Pelodictyon clathratoforme population. 
lidad de la columna de agua a partir de la mezcla completa de la misma. Además de esta especie, en la comunidad también se observaron otros representantes de las bacterias verdes del azufre como Chlorobium limicola y el consorcio "Chlorochromatiurn aggregatum". Entre las bacterias púrpuras del azufre destacaron Chromatium okenii, Thiocapsa roseopersicina y Thiodictyon elegans.

Otra visión de la evolución de las diferentes comunidades microbianas fotosintéticas en la laguna se muestra en la figura 9 donde se han escogido algunos perfiles representativos de los distintos periodos comentados. En este sentido hay que hacer especial hincapié en la distribución y abundancia de los diferentes comunidades microbianas estudiadas. El primer periodo (marzo 1992) estuvo dominado por el "bloom" fitoplanctónico, alcanzando máximos

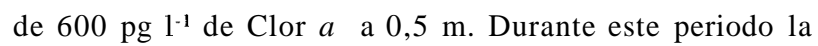
comunidad de bacterias fototróficas se encontraba en fase de desarrollo. A partir del mes de mayo, tras la desaparición del filtro biológico que constituían las algas, la población de Pelodictyon empezó un rápido crecimiento que

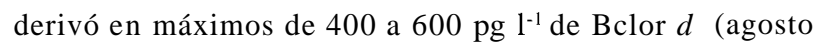
y septiembre). Durante la segunda mitad del período de estratificación, las intensidades de luz disponibles para las diferentes comunidades fueron muy inferiores a las registradas en primavera debido a la presencia de la población de Lemna en la superficie de la laguna. La atenuación de la luz, aunque evidente, no significó un factor limitante para las bacterias verdes del azufre acostumbradas a intensidades de luz considerablemente más bajas que las necesarias para mantener el crecimiento fitoplanctónico

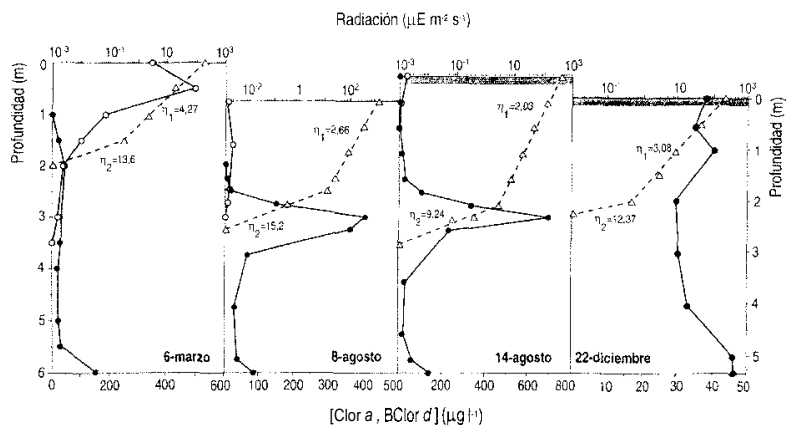

FIGURA 9.- Perfiles verticales de la concentración de Clor a $(\mathrm{O})$, BClor d (O) y de la penetración de la luz (A) en la laguna en diferentes momentos del ciclo anual estudiado. La línea gris muestra el área ocupada por la población de Lemna minor.

FIGURE 9.- Vertical profiles of $\mathrm{Chl}$ a $(\mathrm{O})$ and BClor d $(\mathrm{O})$ concentrations and light penetration (A) in La Coromina at different moments of the study period. Grey line shows the location of the Lemna minor population.
(MONTESINOS \& VAN GEMERDEN, 1986; PFENNIG, 1989).

Un fenómeno a destacar al respecto de la ecología microbiana de la laguna es la gran abundancia de especies vacuoladas dominantes dentro de la comunidad bacteriana fotosintética. A excepción hecha de Chromatium, que posee flagelación polar y que por tanto es móvil, tanto Pelodictyon, como Thiocapsa y Thiodictyon presentan células con vacuolas de gas. Además, Pelodictyon es capaz de realizar divisiones ternarias que posibilitan la formación de estructuras coloniales en forma de red tridimensional (PFENNIG \& COHEN-BAZIRE, 1967; KONDRATIEVA et al., 1992). Esta dominancia de formas bacterianas vacuoladas puede considerarse como una estrategia de las células bacterianas para situarse en el lugar óptimo, en base a sus requerimientos de luz y sulfhídrico, en la columna de agua. ABELLA \& GARCÍA-GIL (1988) sugirieron el hecho de que la capacidad de Pelodictyon para desarrollar estructuras coloniales tridimensionales, así como la posesión de vacuolas de gas representase un mecanismo de enriquecimiento de la población en ecosistemas donde los gradientes de densidad son suaves. En presencia de gradientes bruscos de densidad, por ejemplo en lagos meromícticos, las poblaciones de bacterias fototróficas verdes del azufre no suelen pertenecer a formas vacuoladas sino a especies del tipo Chlorobium, las quales se acumulan pasivamente en la zona de la quimioclina (MONTESINOS, 1981; MONTESINOS \& VAN GEMERDEN, 1986; GUERRERO et al., 1987).

\section{Dinámica limnológica}

La dinámica de la laguna desde el punto de vista limnológico presenta una serie de características que son comunes a ecosistemas acuáticos de este tipo: i) circulación del agua limitada con tiempos de residencia elevados; ii) regímenes de oxígeno desequilibrados, con fluctuaciones extremas y máximos y mínimos diferenciados; iii) aporte de nutrientes elevado, con regímenes desequilibrados; iv) productividad muy alta durante determinadas épocas del año seguidas por periodos de intensa y única actividad respiradora y v) cadenas tróficas cortas (BARICA, 1979). Las constantes oscilaciones en el nivel de agua y las fluctuaciones de los regímenes de oxígeno y nutrientes que se registraron en La Coromina constituyen un nivel de dificultad añadido para el estudio de la laguna. La dinámica de La Coromina no puede predecirse tan fácilmente como puede serlo en otros ecosistemas acuáticos 


\begin{tabular}{|c|c|c|}
\hline & 1988 & 1992 \\
\hline Prof. máxima (m) & 7.7 & 7,1 \\
\hline $\begin{array}{l}\text { Temperatura ("C) } \\
\text { máx. epilimnion } \\
\text { mín. hipolimnion }\end{array}$ & $\begin{array}{r}22,5 \\
1,2\end{array}$ & $\begin{array}{r}23,1 \\
6,1\end{array}$ \\
\hline $\begin{array}{l}\text { Conductividad ( } \mu \mathrm{S} \mathrm{cm} \text { ') } \\
\text { máx. epilimnion } \\
\text { mín. hipolimnion }\end{array}$ & $\begin{array}{l}990 \\
304\end{array}$ & $\begin{array}{r}1400 \\
300\end{array}$ \\
\hline $\begin{array}{l}\mathrm{pH} \\
\text { máximo } \\
\text { mínimo }\end{array}$ & $\begin{array}{l}8,7 \\
6,2\end{array}$ & $\begin{array}{l}9.4 \\
6.6\end{array}$ \\
\hline $\begin{array}{l}\text { Bh }(m V) \\
\text { máximo } \\
\text { minimo }\end{array}$ & $\begin{array}{r}450 \\
-347\end{array}$ & $\begin{array}{r}265 \\
-358\end{array}$ \\
\hline$[\mathrm{O}$,$] medias \left(\mathrm{g} \mathrm{m}^{-3}\right)$ & 4,6 & $>20$ \\
\hline $\begin{array}{l}\text { [SO; medias }\left(\mathrm{mmol} \mathrm{m}^{-3}\right) \\
\text { epilimnion } \\
\text { hipolimnion }\end{array}$ & $\begin{array}{r}1000 \\
600\end{array}$ & $\begin{array}{l}2000 \\
1500\end{array}$ \\
\hline$\left[\mathrm{H}_{2} \mathrm{~S}\right]$ medias $\left(\mathrm{mmolm}^{-3}\right)$ & 1172 & 978 \\
\hline $\begin{array}{l}{[\mathrm{PT}] \text { medias }\left(\mathrm{mmolm}^{3}\right)} \\
\text { epilimnion } \\
\text { hipolimnion }\end{array}$ & $\begin{array}{r}8,2 \\
30.9\end{array}$ & $\begin{array}{r}47,0 \\
113,1\end{array}$ \\
\hline $\begin{array}{l}{\left[\mathrm{NH}_{4}^{*}\right] \text { medias }\left(\mathrm{mmolm}^{-3}\right)} \\
\text { epilimnion } \\
\text { hipolimnion }\end{array}$ & $\begin{array}{l}155,3 \\
767,8\end{array}$ & $\begin{array}{c}350 \\
3360,2\end{array}$ \\
\hline $\begin{array}{l}\text { [Clor a] medias }\left(\mathrm{mg} \mathrm{m}^{3}\right) \\
\text { invierno } \\
\text { primavera } \\
\text { verano }\end{array}$ & $\begin{array}{r}52.5 \\
4,3 \\
29,4\end{array}$ & $\begin{array}{r}226,1 \\
426,1 \\
10.3\end{array}$ \\
\hline Máximos algales & marzo-julio & febrero-marzo \\
\hline $\begin{array}{l}{[\text { Bclor } \mathbb{d}] \text { medias }\left(\mathrm{mg} \mathrm{m}^{\cdot 3}\right)} \\
\text { mayo } \\
\text { junio } \\
\text { julio } \\
\text { agosto } \\
\text { septiembre } \\
\text { octubre } \\
\text { noviembre } \\
\text { diciembre }\end{array}$ & $\begin{array}{r}9.0 \\
1,3 \\
78.1 \\
457,1 \\
320,5 \\
119,5 \\
\text { nd } \\
\text { nd }\end{array}$ & $\begin{array}{r}122,5 \\
82.2 \\
16.2 \\
82,5 \\
88,5 \\
43,8 \\
31,4 \\
36,4\end{array}$ \\
\hline
\end{tabular}

TABLA 1.- Comparación entre los principales parámetros físico-químicos y biológicos registrados en la Coromina durante el ciclo anual de 1988 (RIERA, 1988) y los del presente trabajo. Es de destacar el espectacular aumento de los valores de amonio y fósforo total durante los últimos años como consecuencia del incremento en los vertidos orgánicos en la laguna. n.d.: no detectado.

TABLE 1.- Comparison between the main physicho-chemical and biological parameters registered in La Coromina during the annual cycle of 1988 (RIERA, 1988) and those measured during the present study. Note the increased in the ammonia and total phosphorous values as a consequence of the high inputs of organic wastes in the ecosystem. $n$. d.: not detected.

debido a la importancia de dichas fluctuaciones en su ciclo anual.

Comparando algunos de los parámetros estudiados durante el presente trabajo con estudios previos realizados en La Coromina (RIERA, 1988) puede obtenerse una visión global de la evolución de la misma en los últimos años (Tabla 1). Atendiendo a algunos indicadores tróficos (fósforo total, amonio y Clor a) se pone de manifiesto el cambio sufrido por la laguna y se constata el proceso de degradación que ha sufrido durante los últimos años debido al vertido incontrolado de los residuos orgánicos. Destacables son el aumento en las concentraciones de fósforo total (de 8,2 a $47 \mathrm{mmol} \mathrm{m}^{-3}$ de P-PT en el epilimnion y de 30,9 a $113 \mathrm{mmol} \mathrm{m}^{-3}$ de P-PT en el hipolim-

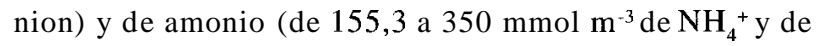

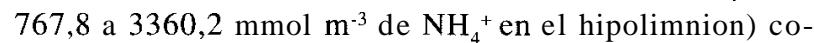
mo reflejo de la masiva entrada de nutrientes y la intensa actividad microbiana respiradora y fermentadora a nivel de sedimento. La elevada carga de nutrientes favoreció el desarrollo de comunidades fitoplanctónicas que alcanzaron valores de 226,1 y $426,1 \mathrm{mg} \mathrm{m}^{-3}$ de Clor a en invierno y primavera de 1992, respectivamente. Estos valores son netamente superiores a los registrados en 1988 (52,5 y $4,3 \mathrm{mg} \mathrm{m}^{-3}$ de Clor a en invierno y primavera, respectivamente). La posterior sedimentación de estas floraciones algales repercute obviamente en un aumento de la carga interna de nutrientes, fenómeno que se tiene que sumar a la ya de por sí elevada entrada externa de los mismos.

Actualmente La Coromina mantiene la anoxia en la totalidad de la columna de agua y aunque puede considerarse un ecosistema muerto desde el punto de vista eucariótico, no es así desde el punto de vista bacteriano. Con el establecimiento de la anoxia en la columna de agua se pasó de un ciclo de vida eucariótico, dominado por una producción primaria algal y una producción secundaria zooplanctónica, a un ciclo de vida procariótico, dominado por procesos microbianos fotosintéticos, fermentadores y respiradores. La Coromina puede compararse actualmente, al igual que ocurre con la laguna del Sisó (Banyoles, Girona), al hipolimnion anóxico de un lago, localizado en plena superficie. El estudio de este ecosistema y de su dinámica limnológica puede resultar interesante para conocer mejor las zonas anóxicas de los lagos estratificados y su efecto en los compartimentos superiores del mismo. Queda por ver sin embargo si la situación en la que se encuentra actualmente la laguna será permanente o si recuperará su estado anterior. En este caso, La Coromina actuaría como un ecosistema oscilante donde las fluctuaciones de su dinámica limnológica comportan bruscas variaciones en las comunidades biológicas que en ella se desarrollan. 


\section{BIBLIOGRAFÍA}

ABEllá, C. A., A. C. DUTRAS \& R. C. BRUNET, 1986. Balanç del fosfat soluble i dels paràmetres de contaminacio bacteriològica a l'Estany de Banyoles durant el periode primavera-estiu de 1984. En: Primeres Jornades sobre l'Estany de Banyoles, pp: 159-171.

ABELLÁ, C. A. \& L. J. GARCIA-GIL, 1988. Diel migration as a mechanism for enrichment of natural populations of branching species of Pelodictyon. En: Green Photosynthetic Bacteria (J. M. OLSON, J. G. ORMEROD, J. AMESZ, E. STAKEBRANDT \& H. G. TRUPER, eds.), Plenum Press, pp. 269-285.

ASTM STANDARDS, 1981. Annual Book of ASTM Standards, parte 31: Water. American Society for Testing and Materials, pp. 601-602

BARICA, J., 1980. Why hypertrophic ecosystems? En: Hypertrophic Ecosystems. S.I.L. Workshop on Hypertrophic Ecosystems, Developments on Hydrobiology Series (J. BARICA \& L. MUR, eds.), Kluwer Academic Publishers Group, pp. 9-11.

BRUNET. R. C., L. J. GARCIA-GIL Y C. A. ABELLÁ, 1990. Estudio comparado de parámetros de eutrofización en recintos experimentales de la laguna del Vilar (Banyoles). Actas del V Congreso Español de Limnología. Sci. gerundensis, 16/2: 123-132.

GARCÍA-GIL, L. J., C. A. ABELLÁ Y R. MORENOAMICH, 1990. Aporte de nutrientes por los tributarios superficiales del lago de Banyoles. Actas del V Congreso Español de Limnologia. Sci. gerundensis, vol 16/2: 141155.

GLIWICZ, Z. M. \& A. KOWALCZEWSKI, 1981. Epilimnetic and hypolimnetic symptoms of eutrophication in Great mazurian lakes, Poland. Freshwater Biology, 11: 425-433.

GLOE, A. N., N. PFENNIG, H. BROCKMAN \& W. TROWITZSCH, 1975. A new bacteriochlorophyll from brown-colored Chlorobiaceae. Arch. Microbiol. 102: 103109.

GOLTERMAN, H. L., R. S. CLYMO \& M. A. M. OHNSTAD, 1978. Methods for physical \& chemical analysis of freshwaters. IBP Handbook $\mathrm{N}^{\circ} 8,2^{\prime \prime}$ edición. Blackwell Scientific Publications.

GUERRERO, R., C. PEDRÓS-ALIÓ, I. ESTEVE \& J. MAS, 1987. Communities of phototrophic bacteria in lakes of the spanish mediterranean region. En: Ecology of photosynthetic prokaryotes (T. LINDHOLM, ed.), Acta Academiae Aboensis, 47: 125-151.
HENDERSON-SELLERS, B. \& H. R. MARKLAND, 1987. Decaying lakes. The origins and controls of cultural eutrophication. (B. HENDERSON-SELLERS \& H. R. MARKLAND, eds.), John Wiley \& Sons.

IMBODEN, D. M., 1974. Phosphorous model for lake eutrophication. Limnol. Oceanogr., 19: 297-304.

JøRGENSEN, B. B., J. G. KUENEN \& Y. COHEN, 1979. Microbial transformations of sulfur compounds in a stratified lake (Solar Lake, Sinai). Limnol. Oceanogr. 24: 799-822.

JØRGENSEN, S. E., 1976. A eutrophication model for a lake. Ecol. Model., 2: 147-165.

KAMP-NIELSEN, L., 1980. The influence of sediments on changed phosphorous loading to hypertrophic lake Glumsø. En: Hypertrophic Ecosystems, S.I.L. Workshop on Hypertrophic Ecosystems, Developments on Hydrobiology Series. (J. BARICA \& L. MUR, eds.), Kluwer Academic Publishers Group, pp. 29-37.

KONDRATIEVA, E. N., N. PFENNIG \& H. G. TRUPER, 1992. The phototrophic prokaryots. En: The Prokaryotes. A Handbook on the Biology of Bacteria: Ecophisiology, Isolation. Identification, Applications. (A. BALLOWS, H. G. TRUPER, M. DWORKIN, W. HARDEN \& K. H. SCLEIFER, eds.), 2" edición, Springer-Verlag, pp. 312-331.

MARGALEF, R., 1983. Limnología. Ed. Omega, Barcelona

MIDDLEBROOKS, E. J., D. H. FALKENBORG \& T. E. MALONEY, 1975. Modeling the eutrophication process. Ann Arbor Science Publishers Inc.

MONTESINOS, E., 1981. Crecimiento y actividad de las bacterias fotosintéticas del azufre en relación con gradientes físico-químicos en ecosistemas acuáticos. Actas del primer Congreso Español de Limnología, pp: 131-137.

MONTESINOS, E. \& H. VAN GEMERDEN, 1986. The distribution and metabolism of planktonic phototrophic bacteria. Proc. IV ISME, pp. 349-359.

PACHMAYR, F., 1960. Vorkomnien und Bestimmng von Schwefelverbindungen in Mineralwasser. Tesis Doctoral. Universidad de Munich.

PFENNIG, N. \& G. COHEN-BAZIRE, 1967. Some properties of the Green Bacterium Pelodictyon clathratiforme. Arch. Microbiol, 59: 226-236.

PFENNIG, N., 1989. Ecology of phototrophic purple and green sulfur bacteria. En: Autotrophic Bacteria, $(\mathrm{H}$. $G$. SCHLEGEL \& B. BOWIEN, eds.). Springer-Vcrlag, pp 97-116.

RIERA, X. G., 1988. Interrelació entre els cicles del 
carhoni i el sofre en amhients sulfatats. Microorganismes implicats. Tesina de licenciatura. Instituto do Ecología Acuática. Universidad Autónoma de Barcelona.

SAS, H., 1989. Lake restoration by reduction of $n u-$ trient loading: expectutions, experiences, extrapolation/coordination. St. Agustin: Academia-Verl. Richarz GmbH, 1989.

SMITH J. H. \& A. BENÍTEZ, 1975. Chlorophylls. Analysis in plant materials. En: Modern mcthods in plant analysis. VH Springer-verlag.

STEEMANN-NIELSEN, E., 1962. On the maximum quantity of plankton chlorophyll per surface unit of a lake or the sea. Int. Rev. ges. Hydrohiol., 47: 333-338.

TAKAHASHI, M. \& S. ICHIMURA, 1970. Photosynthetic properties and growth of photosynthetic sulfur bacteria in lakes. Limnol. Oceanogr., 15: 929-944.

VOLLENWEIDER, R. A., 1968. Scientific fundamentals of the eutrophication of lakes and flowing waters with particular reference to nitrogen and phosphorous as factors in eutrophication. Organization Economic Cooperation and Development, París.

VOLLENWEIDER, R. A., 1982. Eutrophication of waters: monitoring, assesment and control. Organization Economic Cooperation and Development. 
